\title{
The Idea of an Innovated Concept of the Košice Geothermal Project
}

\author{
Alena Bujanská, László Böszörményi \\ Technical University of Košice \\ Civil Engineering Faculty, Institute of Environmental Engineering \\ e-mail: a.bujanska@gmail.com, ladislav.boszormenyi@tuke.sk
}

\begin{abstract}
Slovakia has very limited amounts of fossil resources. However, it has a relatively high potential of geothermal energy which use is far below its possibilities. The most abundant geothermal resource, not only in Slovakia but throughout the central Europe, is Košice basin. Since the publication of the first ideas about the ambitious goal to exploit the geothermal potential of this site, 20 years has passed and three geothermal wells has been made but without any progress. In the article the authors present the idea of a fundamental change in the approach to improve the energy and economic efficiency of the project.
\end{abstract}

Key words: geothermal resource, Organic Rankine Cycle (ORC), hybrid heat power plant

\section{Introduction}

Košice basin, with the potential of about $300 \mathrm{MW}$, is the most promising location for geothermal energy use in Central Europe. Using this potential, even partially, Slovak energy sector could celebrate a great success. But it is not [7].

Recently, the media has often hyped disappointment of Olšava microregion competent representatives over the fact that promised geothermal energy for the secondary use is nowhere in sight and the fate of the geothermal power plant, which should have been using energy potential of the existing geothermal wells since 2011, is still uncertain.

This failure inspired thoughts about the effectiveness of recently promoted concept of the geothermal project and the possibilities of enhancing it.

The first extensive study on the use of geothermal energy potential of the Košice basin has been prepared in 1991 under Energoprojekt, in cooperation with the company ORMAT and the State Geological Institute of Dionyz Štur (GÚDŠ). According to the study, the geothermal power plant with 24 power modules OEC (ORMAT ENERGY CONVERTER), with a total capacity of $31.2 \mathrm{MW}$ (with temperature around $130^{\circ} \mathrm{C}$, according to realistic assumptions made by GÚDŠ experts) or $42 \mathrm{MW}$ (with temperature around $140^{\circ} \mathrm{C}$ according to the optimistic estimate by the technology supplier FY ORMAT) should have been built in four 
phases and at four locations (Bidovce, Slančík, Blažice, Slanská Huta). Results of the study did not confirm euphoric expectations of cheap electricity production, so this alternative geothermal project was quickly forgotten.

We state these facts because the planned electricity production was based on the technology that is known as ORC (Organic Rankine Cycle). In addition to the expected, and quite insignificant, power of $3.5 \mathrm{MW}$, we failed to find details about the technical solutions for the planned geothermal power plant, which, under the current plan, should be built at Durkov. Based on the parameters of geothermal resources it should use in the same technology.

We should note that this technology uses special kind of working substance which is some form of organic liquid with a low boiling point. Accordingly, contrary to conventional thermal cycle operating with water, also known as the inorganic Rankine cycle, it uses lowtemperature sources to produce electricity. The efficiency of electricity production using this expensive technology is uncompromisingly restricted under the second law of thermodynamics by temperature. At temperatures of the primary carrier of geothermal energy, the efficiency achieved in Košice basin would be comparable to that of lower quality photovoltaic cells. While investment and operating cost ratio of geothermal power plant is too high, the solar radiation is available free of charge. It can be said that the ORC technology is particularly suitable for waste heat recovery, the carrier of which is also available for free or at low cost and possibly at a higher temperature. Given the facts proposed above, we believe that in Košice basin's conditions it is not possible to achieve an acceptable economic efficiency of electricity production using this technology at an acceptable sale price of electricity. This is evidenced by the results of a long forgotten study by Energoprojekt.

It seems that authors of the current study on the construction of the geothermal power plant at Durkov underestimated the risk of low economic efficiency in the preparatory phase. From the statement of the spokesman of SPP (Slovak Gas Industry), joint stock company, the owner of the existing geothermal wells, it can be concluded that this fact is becoming a problem.

After the implementation of the three wells GTD 1,2,3, the temperature of about $130^{\circ} \mathrm{C}$ was confirmed. The production of electricity by ORC technology is at such temperature indeed technically possible, but with low energy and economic efficiency. Since this energy is available in the form of heat, it is logical that its use for the heat supply may be more efficient. Thus was born the idea of a new use: powering Košice district heating system with geothermal heat. Various alternatives were possible, but each of them had a weakness - the need to build district heating network in TEKO (Košice combined heat and power plant), the implementation of which proved to be quite difficult.

For poorly known issues, there has been no or virtually no progress in the use of geothermal energy for district heating system for many years. Therefore, SPP decided to radically change the concept of the project and divided it into two phases. The first phase should have used the potential of three existing wells, primarily for the production of electricity and secondary for heat supply in the near vicinity.

We are interested in the issue of primary use of geothermal energy from existing wells. We were surprised by authors' courage to return to using ORC technology, despite the known outcome of the first study also because at substantially less power output the risk of low economic efficiency is even higher. It turns out that that courage was excessive. 
The fate of primary capacity utilization of existing geothermal wells to produce electricity in geothermal power plant at Durkov is after four years slip still uncertain. Consequently, the heat supply in the near vicinity cannot be implemented as well.

Acceptable measures to enhance the economic efficiency of the project for the planned technical solutions are well known:

- $\quad$ reducing acquisition costs - this option is quite limited if we exclude a suspicion of „CT-syndrome“ taking place during the original calculation of the acquisition costs

- $\quad$ increasing revenues from electricity sales by increasing the production - it is rather hypothetical than real possibility, because the authors probably counted with the possibility of maximal reasonably achievable production through the proposed technical solution.

The easiest and most effective measure would be to increase the income from the sale of electricity by increasing the price set by the Office for Network Industries. The problem of high cost of geothermal electricity would thus be passed on to consumers, as was the case with solar electricity. However, we should not go by this path because currently planned guaranteed price is already significantly subsidized and creates upward pressure on prices for final consumers.

\section{Real possibilities for increasing the efficiency of the first phase of using geothermal resources are likely to be in the radical change of the basic concepts.}

Regarding the primary capacity utilization of existing wells in the first phase of the project, we do not have to give up the possibility of electricity production. Instead of geothermal power plants based on ORC technology it would be more correct to build a kind of hybrid power plant. In our case it would differ from the standard condensing power plant with traditional steam cycle was in that the geothermal heat, as a low temperature heat, would be used to heat the condensate instead of steam. (Basically it's just a fairly simple replacement of the heat exchanger/s. The steam-water heat exchanger is replaced by the water-water heat exchanger, which is even more effective.)

High temperature heat supplied to the thermal cycle could be preferably provided by burning biomass, optionally in combination with other (fossil) fuels.

\section{An alternative innovative idea for the conception of the project's first phase}

Replacing the project for the construction of geothermal ORC power plant with the hybrid thermal power plant with conventional inorganic Rankine cycle could be a meaningful measure to increase energy and economic efficiency of the existing geothermal wells' capacity to produce electricity (primary use) and to supply district heating appliances in the near Olšava microregion (secondary use)

In order to clearly confirm this hypothesis, or vice versa, disprove it, it would be necessary to develop a serious detailed comparative analysis of the original and proposed innovative concept of the first phase. In doing so, the main parameters of the proposed concept must 
ensure equal conditions for the secondary use - heat supply. (We assume, therefore, that the innovation refers only to the primary use of the available geothermal power consumption.) It would be necessary to take a detailed feasibility study carried out for the current intentions of the project's first phase of the project. That, however, according to the owner of Geotherm, joint stock company, contains confidential information and therefore it was not given to us.

Therefore, we were forced to rely on publicly available information which is incomplete and may be unreliable. Therefore, is it not possible to draw up a comparative study of the feasibility of an innovative concept of the first phase of the project. We can only establish the main parameters so as to ensure adequate possibility of secondary use of residual heat. These could be used directly or after some corrections as baseline data for the feasibility study carried out by a team of professionals.

According to available information, the concept of project's I. phase could be illustrated by the scheme shown in Fig.1. We assume the following input:

- $\quad$ the number of geothermal doublets: 2

- $\quad$ flow rate of each well: $55 \mathrm{l} / \mathrm{s}$

- wellhead temperature of the primary carrier of geothermal energy: $t_{g e, p, 1}=130^{\circ} \mathrm{C}[7]$

- temperature of cooled secondary carrier of geothermal energy: $t_{g e, s, 2}=60^{\circ} \mathrm{C}$.

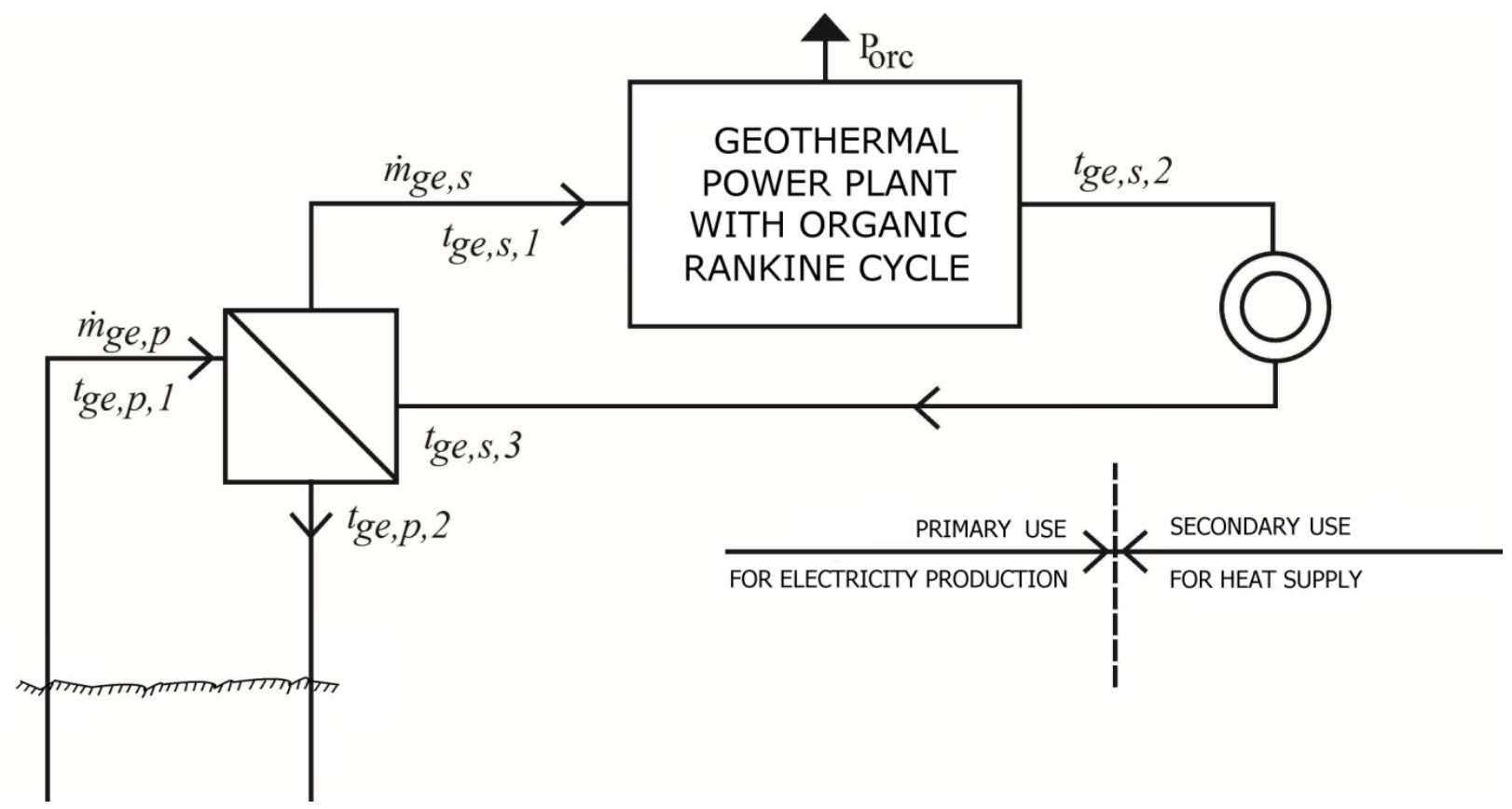

Figure 1: A simplified diagram of the current concept principle of existing geothermal wells capacity utilization 
For this figure's data shall apply:

- mass flow in the geothermal primary circuit: $m_{g e, p}^{\bullet}=110 \mathrm{~kg} / \mathrm{s}$

- mass flow in the secondary circuit: $m_{g e, s}^{\bullet}=110 \mathrm{~kg} / \mathrm{s}$

- temperature of the extracted primary carrier of geothermal energy (at the transfer station): $t_{g e, p, 1}=130^{\circ} \mathrm{C}$

- given the problems caused by mineralization of geothermal water we should consider relatively large temperature differences in the transmission of heat, which is estimated at $3 \mathrm{~K}$; so the temperature of the secondary carrier of geothermal energy at the input into the geothermal ORC power plant shall be $t_{g e, s, 1}=127^{\circ} \mathrm{C}$

- temperature of the secondary carrier of geothermal energy used for heat supply: $t_{g e, s, 2}=60^{\circ} \mathrm{C}$

- temperature of the secondary carrier of geothermal energy returned to the heat exchanger station: $t_{g e, s, 2}=30^{\circ} \mathrm{C}$

- temperature of the primary carrier of geothermal energy transmitted from the heat exchanger station to re-injection wells: $t_{g e, p, 2}=33^{\circ} \mathrm{C}$

Under these conditions electric power of ORC power plant can be calculated by a simple relation:

$$
P_{O R C}=\eta_{O R C} \cdot \mathbf{Q}_{g e, s}^{\bullet}=\eta_{O R C} \cdot c \cdot\left(t_{g e, s, 1}-t_{g e, 2}\right)
$$

where the specific heat capacity of water is: $c=4,187 \mathrm{~kJ} /(\mathrm{kgK})$ and the effectiveness can be estimated, according to past experience, to $\eta_{O R C}=0,11$ and for the electric power of ORC power plant we get:

$$
P_{\text {ORC }}=0,11.110 .4 \cdot 187 .(127-60)=3394 \mathrm{~kW}=3,4 \mathrm{MW}
$$

which, according to unverified sources, roughly corresponds to the value of the planned feasibility study (3,49 MW).

The obvious drawback of this approach is the high investment, reportedly up to about 30 million. $€$, which, even in the absence of expenditure on fuel, generates relatively low annual income.

The most effective tool for improving the economic efficiency of the project is therefore to increase annual revenues from electricity sales. The essence of the innovative concept proposal is to replace geothermal ORC power plant by hybrid thermal power plant with geothermal support. A simplified principle diagram of this concept is shown in Fig. 2. 


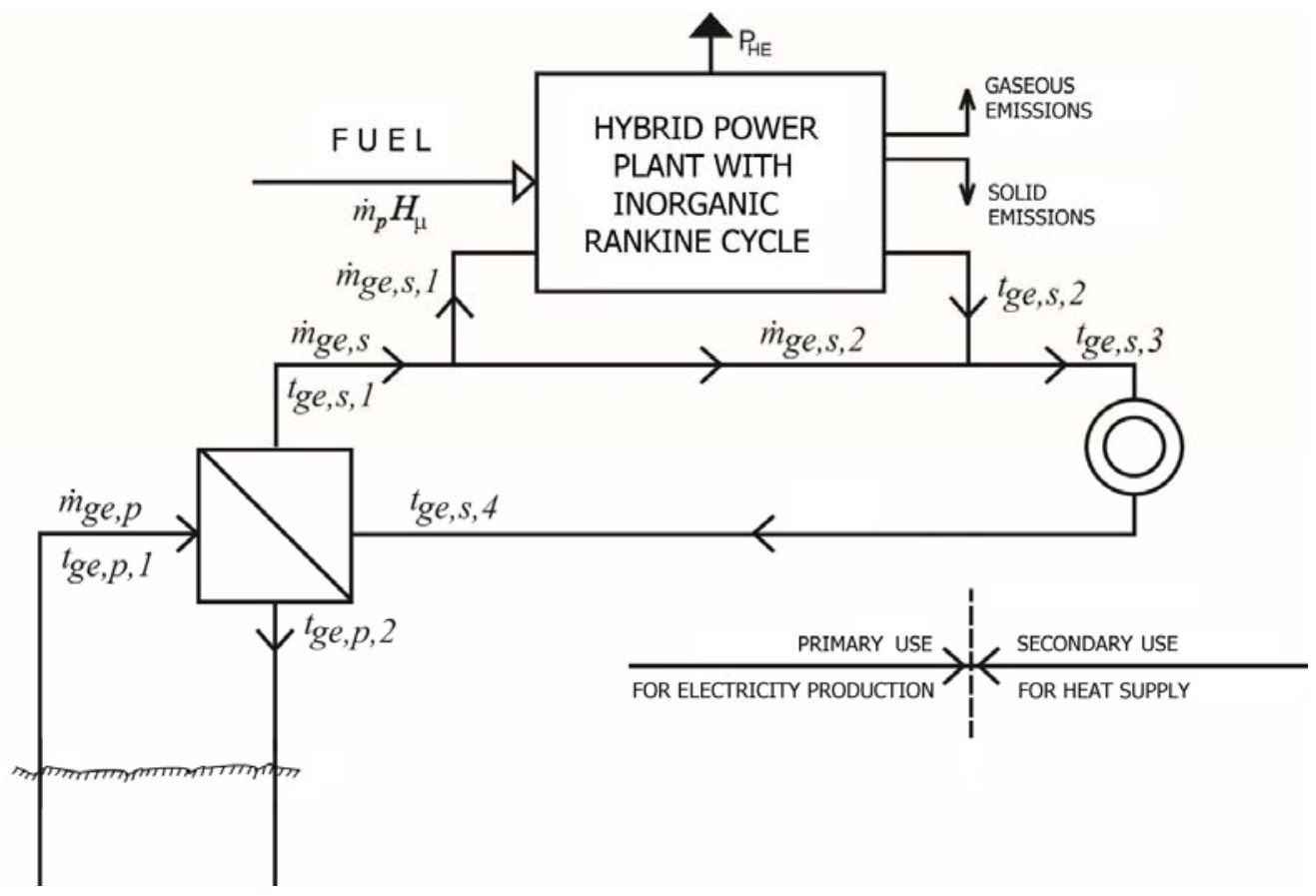

Figure 2: A simplified principle diagram of innovated concept of the project using the capacity of already existing geothermal wells

\section{Determining the flow of the secondary carrier of geothermal energy necessary for operating a hybrid thermal power plant}

In the hybrid thermal power plants, geothermal energy is supplied to the heat loop by heating the condensate, whose temperature is usually about $30^{\circ} \mathrm{C}$. Therefore, the flow of the secondary carrier of geothermal energy is cooled to approximately that temperature. This use of geothermal energy is therefore more efficient. One degree from the same flow of secondary geothermal energy carrier uses about twice as much heat output as the ORC process, in which geothermal energy is used typically only up to about $60^{\circ} \mathrm{C}$.

Given these facts, only a part of the flow of the secondary carrier of geothermal energy is supplied to the hybrid thermal power plant, $m_{g e, s, 1}^{\bullet}$, which after cooling, is again joined with the rest of the flow $m_{g e, s, 2}^{\bullet}$. In order to ensure equal conditions for the use of the heat supply, the resulting temperature shall be the same as the temperature at which the secondary carrier of geothermal energy is delivered to the consumer system under the original concept (Fig.1).

The flow $m_{g e, s, 1}^{\bullet}$ rate can be determined from the following simple enthalpy of mixing balance:

$$
m_{g e, s, 1}^{\bullet} \cdot \text { c. } t_{g e, s, 2}+m_{g e, s, 2}^{\bullet} . c . t_{g e, s, 1}=m_{g e, s}^{\bullet} . c . t_{g e, s, 2}
$$

if mass balance is effective at the time: 


$$
m_{g e, s}^{\bullet}=m_{g e, s, 1}^{\bullet}+m_{g e, s, 2}^{\bullet}
$$

From these equations for the current holder of the secondary geothermal energy supplied to the hybrid thermal power plant it is clear:

$$
m_{g e, s, \mathbf{1}}^{\bullet}=\frac{m_{g e, s}^{\bullet}\left(t_{g e, s, \mathbf{1}}-t_{g e, s, 3}\right)}{t_{g e, s, \mathbf{1}}-t_{g e, s, 2}}
$$

Provided that the pressure in the condenser will be $p_{k}=0,004 \mathrm{MPa}$, we be expect condensate temperature $t_{k}=29^{\circ} \mathrm{C}$ and with cooling the secondary carrier of geothermal energy when heating the condensate $t_{g e, s, 2}=31^{\circ} \mathrm{C}$.

Under these conditions for the flow rate of the secondary carrier of geothermal energy supplied to the hybrid plants we get:

$$
m_{g e, s, 1}^{\cdot}=\frac{110(127-60)}{127-31}=76,8 \mathrm{~kg} / \mathrm{s}
$$

\section{Determining performance of the hybrid thermal power plant}

The flow of condensate in the heat exchanger can be considered equal to the flow of the secondary carrier of geothermal energy, thus

$$
m_{k}^{\bullet}=m_{g e, s, 1}^{\bullet}=76,8 \mathrm{~kg} / \mathrm{s}
$$

We consider the need for steam to drive a steam jet vacuum pump to ensure the under pressure in the condenser, which is about $2 \%$, and exclude the collection from the steam turbine, we can assume that the turbine expands

$$
m_{a}^{\bullet}=0,98.76,8=75,25 \approx 75 \mathrm{~kg} / \mathrm{s}
$$

steam from the state $\mathbf{a}$ - the admission steam into state $\mathbf{e}$ - emission steam according to the much simplified expansion curve shown in Fig.3

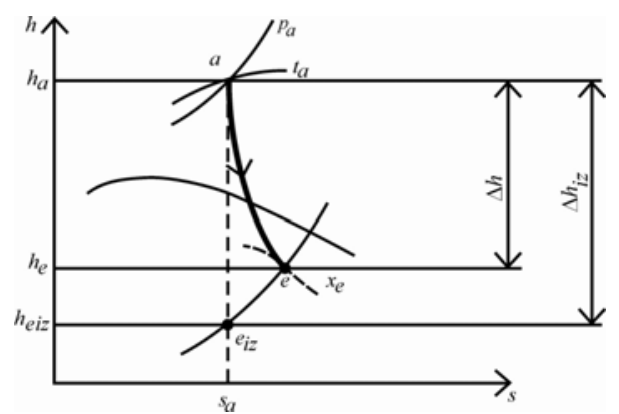

Figure 3: Expansion curve of steam in the turbine of hybrid thermal power plant in the diagram h-s 
From thermodynamic point of view admissions steam is superheated steam (single-phase thermodynamic substance). Its state $\mathbf{a}$ is usually given by pressure and temperature. These values mostly affect the performance of the turbine at a given flow rate of steam. Given the estimated fuel base (biomass, possibly in combination with fossil fuels), their values should be chosen carefully with a margin for possible increases if a supplier of technology considered it justified in order to increase the performance:

- Pressure: $p_{a}=3,6 \mathrm{MPa}$

- Temperature: $t_{a}=440^{\circ} \mathrm{C}$

From the tables of thermodynamic properties of superheated steam we may determine other admission steam's parameters:

- The specific enthalpy: $h_{a}=3314 \mathrm{~kJ} / \mathrm{kg}$

- The specific entropy: $s_{a}=6,9514 \mathrm{~kJ} /(\mathrm{kgK})$

Emission steam is wet steam from thermodynamic point of view. Therefore it is a two-phase material whose condition cannot be precisely determined neither by pressure nor by temperature, as their values are constant from the state of saturated steam until the saturated liquid state.

To determine the status of $\mathbf{e}$ after the expansion of steam in the turbine, we need to identify the state of $\mathbf{e}_{\mathbf{i z}}$ to which the steam would get after the ideal isentropic expansion. In this state we already know the entropy:

$$
s_{e, i z}=s_{a}=6,9514 \mathrm{~kJ} /(\mathrm{kgK})
$$

With this value and dryness:

$$
\chi_{e, \text { iz }}=\frac{s_{a}-s_{k}^{\prime}}{s_{k}^{\prime \prime}-s_{k}^{\prime}}
$$

clearly determines $\mathbf{e}_{\mathbf{i z}}$. To calculate the dryness we have to determine the entropy of saturated liquid from tables of thermodynamic properties:

$$
s_{k}^{\prime}=0,4427 \mathrm{~kJ} /(\mathrm{kgK})
$$

and saturated steam

$$
s_{k}^{\prime \prime}=8,47517 \mathrm{~kJ} /(\mathrm{kgK})
$$

with these values we get the dryness in state $\mathbf{e}_{\mathbf{i z}}$

$$
\chi_{e, i z}=0,812
$$

Using dryness we can determine enthalpy in $\mathbf{e}_{\mathbf{i z}}$ state under the relation:

$$
h_{e, i z}=\chi_{e, i z}\left(h_{k}^{\prime \prime}-h_{k}^{\prime}\right)+h_{k}^{\prime}
$$

We subtract the enthalpy of saturated liquid at a pressure in the condenser 


$$
h_{k}^{\prime}=121,48 \mathrm{~kJ} / \mathrm{kg}
$$

and saturated steam

$$
h_{k}^{\prime \prime}=2554,5 \mathrm{~kJ} / \mathrm{kg}
$$

After calculating the relation (6) we get:

$$
h_{e, i z}=2097,1 \mathrm{~kJ} / \mathrm{kg}
$$

The specific enthalpy of steam emission at the input condenser (state e) can be determined with known values of thermodynamic efficiency which takes into account the loss of irreversibility expansion in the turbine, and is defined by the formula:

$$
\eta_{t d}=\frac{\Delta h}{\Delta h_{i z}}=\frac{h_{a}-h_{e}}{h_{a}-h_{e, i z}}
$$

According to practical experience for the value of the thermodynamic efficiency we can choose with acceptable accuracy

$$
\eta_{t d}=0,85
$$

From the equation (7) we obtain the enthalpy of steam emission:

$$
h_{e}=h_{a}-\eta_{t d}\left(h_{a}-h_{e, \text { iz }}\right)=3314-0,85 .(3314-2097)=2326 \mathrm{~kJ} / \mathrm{kg}
$$

The internal mechanical power of the turbine generated by real, irreversible expansion of steam will be:

$$
P_{i}=m_{a}^{\bullet} \cdot\left(h_{a}-h_{e}\right)=75 \cdot(3314-2326)=74100 \mathrm{~kW} \approx 74 \mathrm{MW}
$$

In addition to the loss caused by irreversibility (thermodynamic losses), we must take into account

- Turbine's mechanical losses with the efficiency $\eta_{m}=0,98$

- generator's power losses with the efficiency $\eta_{g}=0,97$

Electrical power on the generator's terminals (gross output) will be:

$$
P_{s v}=\eta_{m} \cdot \eta_{g} \cdot P_{i}=0,98 \cdot 0,97 \cdot 74=70,3 \approx 70 \mathrm{MW}
$$

The efficiency influences the net power consumption. The efficiency value was, according to previous experience, around

$$
\eta_{v}=0,93
$$

Electrical power output of the hybrid thermal power plant, which can actually feed the power system (net power), will be:

$$
P_{n t}=\eta_{v} \cdot P_{s v}=0,93 \cdot 70=65 \mathrm{MW}
$$




\section{Determining fuel consumption of the hybrid thermal power plant}

Low temperature heat from the geothermal source and high temperature heat released by combustion, preferably by biomass, in particular wood chips and/or pieces of wood are equally involved in the process of electric power generation. Due to great need for fuel, however, we cannot exclude co-incineration of biomass and fossil fuels. To determine the appropriate amount of fuel we need to identify high temperature heat input. The structure of the total heat input is also interesting.

When calculating low temperature heat input we assume that the condensate is heated from a temperature

$$
t_{k, 1}=29^{\circ} \mathrm{C} \text { - the temperature of the saturated liquid at the condensation pressure }
$$

into the temperature

$$
t_{k, 2}=123^{\circ} \mathrm{C} \text { - the temperature of the condensate at the inlet to the feed water tank. }
$$

From the tables of thermodynamic properties of these states we can determine the following enthalpies:

$$
\begin{aligned}
& h\left(t_{k, 1}\right)=121,48 \mathrm{~kJ} / \mathrm{kg} \\
& h\left(t_{k, 2}\right)=512,22 \mathrm{~kJ} / \mathrm{kg}
\end{aligned}
$$

Under these conditions, the low-temperature geothermal power will be:

$$
\begin{gathered}
Q_{g e}^{\bullet}=m_{k}^{\cdot} \cdot\left[h\left(t_{k n}\right)-h\left(t_{k, 1}\right)\right]=76,8 .(512,22-121,48)=30008,8 \mathrm{~kW} \\
Q_{g e}^{\bullet}=30 \mathrm{MW}
\end{gathered}
$$

High temperature heat is fed into the steam turbine circuit from a steam boiler in the fireplace of which burns fuel. We assume that the condensate, as input water, is fed from a supply tank to the boiler after it was heated by geothermal energy. Provided that the state of superheated steam is given by the point $\mathbf{a}$, the boiler must ensure the output:

$$
\begin{gathered}
Q_{k o}^{\bullet}=m_{k}^{\bullet}\left[h_{a}-h\left(t_{k, 2}\right)\right]=76,8 .(3314-512,22)=215177 \mathrm{~kW} \\
Q_{k o}^{\bullet}=215 \mathrm{MW}
\end{gathered}
$$

The need for fuel is determined from the relationship:

$$
m_{p a l}^{\cdot}=\frac{Q_{k o}^{\bullet}}{H_{u} \cdot \eta_{k o}}
$$

where the energetic value of the fuel (dry wood chips with a moisture content up to $30 \%$ ) can be selected according to [6]:

$$
H_{u}=12 \mathrm{MJ} / \mathrm{kg}
$$


Boiler efficiency is usually around 0,85 . Given that we did not consider water leakage from heat circulation, due to which is the flow of feed water is higher that the condensate flow, we expect a slightly lower value

$$
\eta_{k o}=0,83
$$

Under these conditions (8), the amount of needed fuel would be:

$$
m_{p a l}^{\bullet}=\frac{215}{12.0,83}=21,6 \mathrm{~kg} / \mathrm{s}=77,8 \mathrm{t} / \mathrm{h}
$$

This means that the daily operation would consume about 1,866 tons of fuel.

\section{$\underline{\text { Note }}$}

According to the price list of the manufacturer / merchant [6], energetic value of wood chips is $12 \mathrm{MJ}$ $/ \mathrm{kg}$. The reliability of this value is questionable because such low, pessimistic value cannot be found in literary sources. Also the energetic value of less quality firewood is usually higher than

$15 \mathrm{MJ} / \mathrm{kg}$. If we can rely on more realistic value of $14 \mathrm{MJ} / \mathrm{kg}$, the needed fuel would amount to $m_{p a l}^{\cdot}=\frac{215}{14.0,83}=18,5 \mathrm{~kg} / \mathrm{s}=66,6 \mathrm{t} / \mathrm{h}$. Daily operation would then consume 1598 tons of fuel.

\section{Conclusion}

The primary carrier of geothermal energy in Košice basin is available as an enthalpy of thermal waters at temperatures that allows for the use of the direct production of electricity using ORC technology, but due to the second law of thermodynamics they do so with the low efficiency, which is equal to that of lower quality photovoltaic cells. If we consider the high investment intensity of the technology and the high costs of extraction of thermal water from depths of about $3000 \mathrm{~m}$, it must be clear that acceptable economic efficiency of electricity production can only be achieved at a high, possibly unacceptable selling price of the electricity produced. Therefore, the expected unsatisfactory economic efficiency of electricity production in the geothermal power plant, which should have already been built at Durkov, is no surprise, but rather the fact that is to be expected. The surprise is the courage of authors who, despite this fact and the already known results of the first feasibility study, opted for the alternative concept of primary capacity utilization of existing geothermal wells, probably without seriously dealing with the other options.

The aim of the authors of this article was to introduce an innovative concept, in which geothermal energy is used primarily in the hybrid thermal power plant heating the condensate in classical inorganic Rankine cycle. The same condition of the same heat output for the secondary use of residual heat indicates that the performance of such hybrid power plant would in our case be about $70 \mathrm{MW}$, which is 20 times greater than that of the planned geothermal ORC power plant. In doing so, the specific investment costs of the technology are considerably lower. Therefore, higher economic efficiency can be expected.

Ensuring fuel base for such a hybrid power plant based on a combination of biomassgeothermal energy would be obviously quite difficult, since the annual fuel requirement 
ranges from 1500 to 2000 tons. If such need would be unbearably high given the disposable potential of biomass energy, we may think about an alternative or parallel introduction of the following measures:

- incineration of biomass together with fossil fuels,

- electric power reduction in the power plants, which would result in increased heat output for the secondary use of residual heat,

- hybrid power plant based on a combination of inorganic Rankine cycle for the use of high temperature heat from the combustion of biomass and organic cycle for the use of low temperature heat from geothermal sources; this alternative would use a smaller proportion of biomass, but it is questionable whether it can be compensated by increasing the investment performance of the project.

\section{Acknowledgements}

This publication was developed with the support of the operational programme Research and Development for the project: The Center for Integrated Renewable Energy Generation and Supply, under the code ITMS: 26220220064, co-financed from the European Regional Development Fund.

\section{References}

[1] ALAKANGAS, E., BORGSTRÖM, G., FELBER, T., GÖTTLICHER, G., GRAMMELIS, P., HABART, J., HASLINGER, W., et al. Strategic Research Priorities for Biomass Technology (p.60). RHC-Platform. http://www.rhc-platform.org/fileadmin/Publications/Biomass_SRA.pdf

[2] AVSEC, J., NOVOSEL, U., TŠELIČ, U., KONOVŠEK, D. GOLOB, L., ŽERDÍN, F. (2013). Energy potential utilization in the SAS̆A region. 3rd International conference EnRe, Velenje, 2013

[3] BORSUKIEWICZ, GOVDUR. Dual-fluid-hybrid power plant co-powered by low-temperature geothermal water. Geothermics, 39 (2), pp. 170-176.

[4] BRUHN, M., HUENGES, E., ZOELLNER, G. (1999). Hybride Dampfkraftwerk für Stromerzeugung aus regenerativen Energien. In: VDI-Berichte Nr. 1457.

[5] KOHL, T., \& SPECK, R. (2004). Electricity production by geothermal hybrid - plants in lowenthalpy areas. Twenty-Ninth Workshop on Geothermal Reservoir Engineering Stanford University, Stanford, California, January 26-28.

http://www.geothermal-energy.org/pdf/IGAstandard/SGW/2004/Kohl.pdf

[6] Biomass. List of prices.

http://www.biomasa.sk/images/stories/biomasa/cenniky/Cennik\%20such\%C3\%A9\%20\%C5\%A 1tiepky\%20zima\%202012-13.pdf

[7] BÖSZÖRMÉNYI, L., BÖSZÖRMÉNYI, G. (2002). The Perspectives of Geothermal Energy Utilization in District Heating System of Košice City. World Renewable Energy Congress VII, PERGAMON, 2002. 